\title{
Comment on: Pancreaticoduodenectomy for the treatment of pancreatic neoplasms in children: A Pediatric Surgical Oncology Research Collaborative study
}

Nicolas Prud'homme' ${ }^{1}$ Gary Galante ${ }^{2}$, Harmeet Kaur², Marie-Anne Brundler ${ }^{2}$, Paul Beaudry $^{3}$, and Douglas R. Strother ${ }^{3}$

${ }^{1}$ CHU Sainte-Justine

${ }^{2}$ University of Calgary Cumming School of Medicine

${ }^{3}$ Alberta Children's Hospital

April 9, 2021

\section{Hosted file}

Comment on- Pancreaticoduodenectomy for the treatment of pancreatic neoplasms in children- A Pediatric available at https://authorea.com/users/406860/articles/517364-comment-onpancreaticoduodenectomy-for-the-treatment-of-pancreatic-neoplasms-in-children-apediatric-surgical-oncology-research-collaborative-study

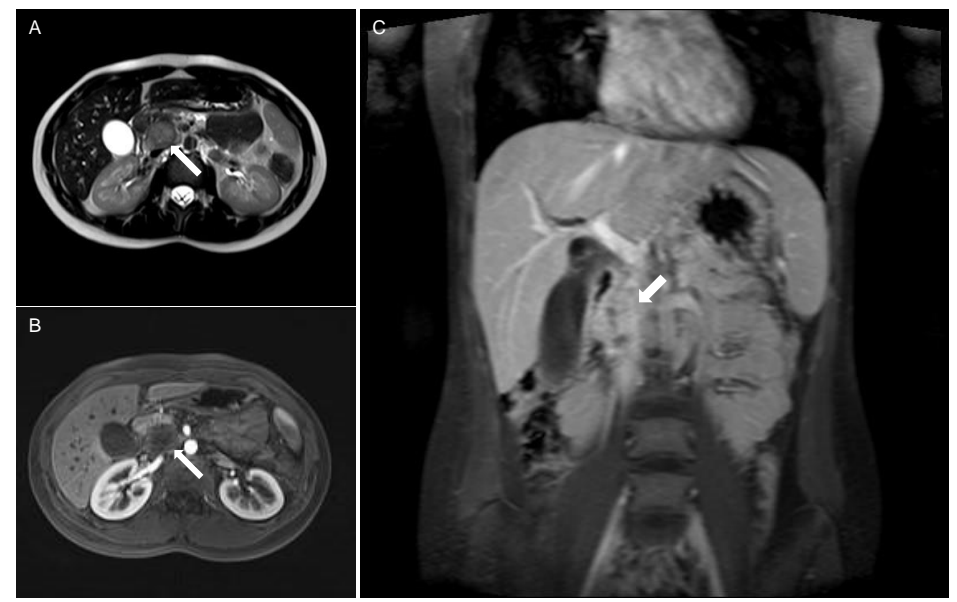

FIGURE 1 A. Axial unenhanced T2 weighted image shows a well-defined heterogeneous hyperintense mass with hypointense rim. B. Contrast enhanced arterial phase fat saturated T1 weighted image demonstrates the lesion as hypointense. C. On a contrast-enhanced portal phase fat saturated T1 weighted image, the lesion demonstrates heterogeneous enhancement. 